\title{
Computer Addiction of Students in Schools under the Office of Basic Education Commission, Bangkok
}

\author{
Kamonmarn Virutsetazin \\ Faculty of Physical Health Education, Srinakarinwirot University, Thailand
}

Copyright $(2016$ by authors, all rights reserved. Authors agree that this article remains permanently open access under the terms of the Creative Commons Attribution License 4.0 International License

\begin{abstract}
This study aimed to detect and propose solution to computer addicted obese students in grades 9-11. In phase I, 288 students (18 schools) were chosen to explore computer addiction and related factors, and 36 volunteers were recruited to brain storm and create strategic management. In phase II, 90 comparison groups (3 schools) and 82 experimental groups(3 schools) attended the training of constructing E-magazines to enhance their creative use of computers. The results showed that in phase $I$, the percentage of computer addiction was 7.39; that were more likely in males $(2.20: 1)$. There were statistically significant differences in the means of computer addiction regarding gender, education level, GPA. and parent's education. There were statistically significant correlations between academic performance, consumption, relaxation, exercise, heath status, and personality and computer addiction. Special and closer attention should be paid to these, and a risk-focus approach should be implemented in introversion-neuroticism personalities. In phrase II, the posttest indicated that there was a statistically significant decrease in computer game use, frequency of use and hours spent on a computer.
\end{abstract}

Keywords Computer Addiction, E-magazines, Student

\section{Background Objectives and Goals}

It is known that we are living in a technological era. Computers have become very important components of life. Computer addiction is a new disorder, described in 1996 by the psychologist Kimberly Young. The most immediate negative effects of computer addiction are social and often occur with students. Young users spend more computer time and generally use computers with great frequency; whether for schoolwork or recreation, computer games or surfing to escape reality, they withdraw from friends and family. There are high rates of failure and drop outs of the students and that affects academic performance. Furthermore, excessive computer use causes them to place more emotional value on events within the artificial world than things happening in the real world. These phenomena threaten their health and interpersonal relationships. Internet addiction describes behavioral factors, e.g., withdrawal and tolerance, and the present article focuses on the maladaptive cognitions associated with Pathological Internet Use. A cognitive-behavioral model of PIU (Davis, R. A. 2000), a model of excessive internet use, distinguishes between specific PIU and generalized PIU (Figure 1). Specific PIU refers to the condition in which an individual pathologically uses the internet for a particular purpose, such as online sex or gambling, whereas generalized PIU describes a more global set of behaviors. The model implies a more important role of cognition in PIU, and describes the means by which PIU is both developed and maintained. Furthermore, it provides a framework for the development of cognitive-behavioral interventions for PIU (Michael, 2004: 34-39). Symptoms of problematic computer addiction and maladaptive patterns of use lead to clinically significant impairment. Physical adverse effects of computer addiction are Carpal Tunnel Syndrome, dry eyes, back and neck aches, severe headaches, and eating irregularities e.g., skipping meals, failure to attend to personal hygiene and sleep disturbance. The addiction enforces social effects, antisocial behavior, the inability to communicate in the real world by depriving the addict of the daily practices involved with interpersonal communication that they become more inclined to develop personality disorders.

Therefore the researcher conducted a study that involved the students in schools under the Office of Basic Education Commission, Bangkok. The study aimed to explore computer addiction behavior and related factors in phase I, and to develop guidelines for computer addiction management, enhance the creativity of computer usage in phase II, as illustrated in the conceptual framework, based on a cognitive behavioral model (Figure 2). 


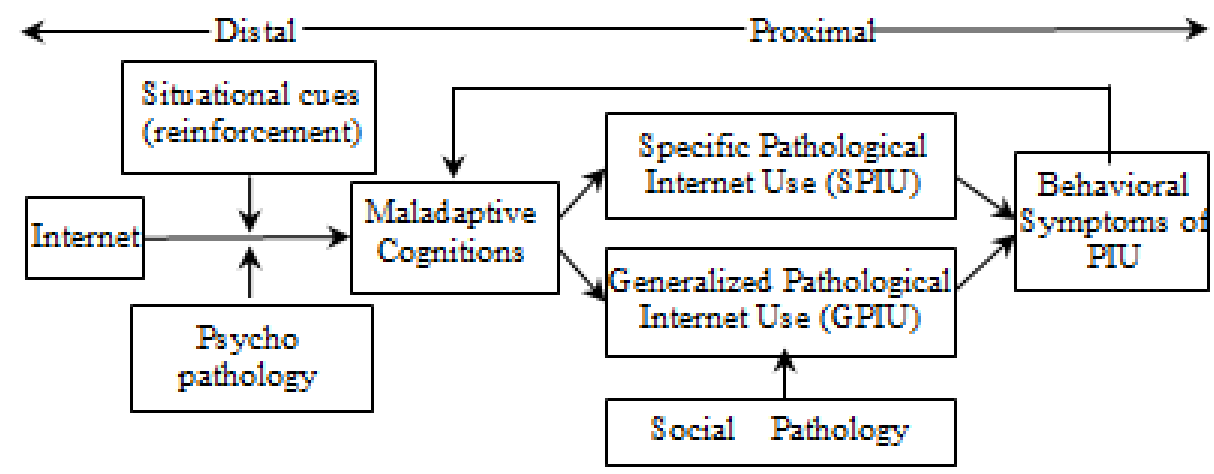

Figure 1. Davis' Cognitive-Behavioral Model of Pathological Internet Use (Davis, R.A. 2000)

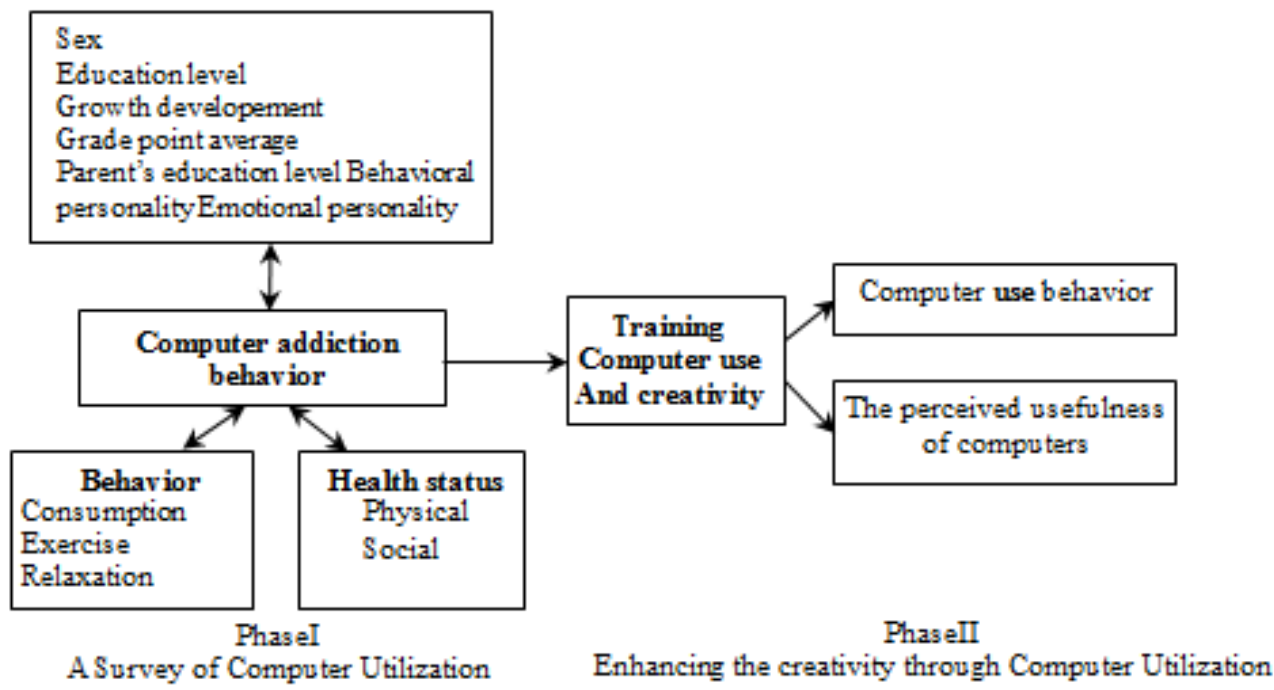

Figure 2. Conceptual framework

\section{Methods}

\section{Participants}

In phase I, 288 out of 3,896 participants were considered to be pathological internet users (7.39\%), screened by Young's diagnostic questionnaire. Phase II, the internet dependent participants were assigned randomly within 2 groups, 85 experimental groups and 89 comparison groups.

\section{Sampling}

The population profile, a total of 207,847 students in 269 schools under the Office of Basic Education Commission, Bangkok, was randomly selected for this research. Using a three-stage sampling procedure, the first stage, 21,318 people in the target population were selected with the CDC BMI-for-age growth, equal to or greater than the 85th percentile (WHO. 2004) and selected the top three schools of obese students out of 3,896. In the second stage (Phase I), 288 sample-computer addicts were selected with Young's screening instrument, and 36 volunteers were recruited to brainstorm by the application of the Appreciation Influence Control process (AIC). In the third stage (Phase II), a quasi-experimental design, the students at the first 6 schools were purposively randomly selected for computer addiction and were assigned randomly into 2 groups; in each group were 85 experimental groups and 89 comparison groups (Figure 3).

\section{Research Methodology}

This study was divided into 2 phases. The first phase was a cross-sectional design, based on stratified random sampling. A total number of 288 students were randomly selected from 18 schools, including 36 recruited volunteers to brainstorm using AIC technique (Smith, W. E. (2001) in order to design the guidelines for solving computer addicted students (Figure 4). The second phase was a quasi-experimental 2-group design(Figure5), based on purposive sampling, equally from 3 schools; a total number of 82 experimental groups attended the training of constructing E-magazines for 8 hours over 4 weeks(Figure6), and 90 comparison groups were selected. 


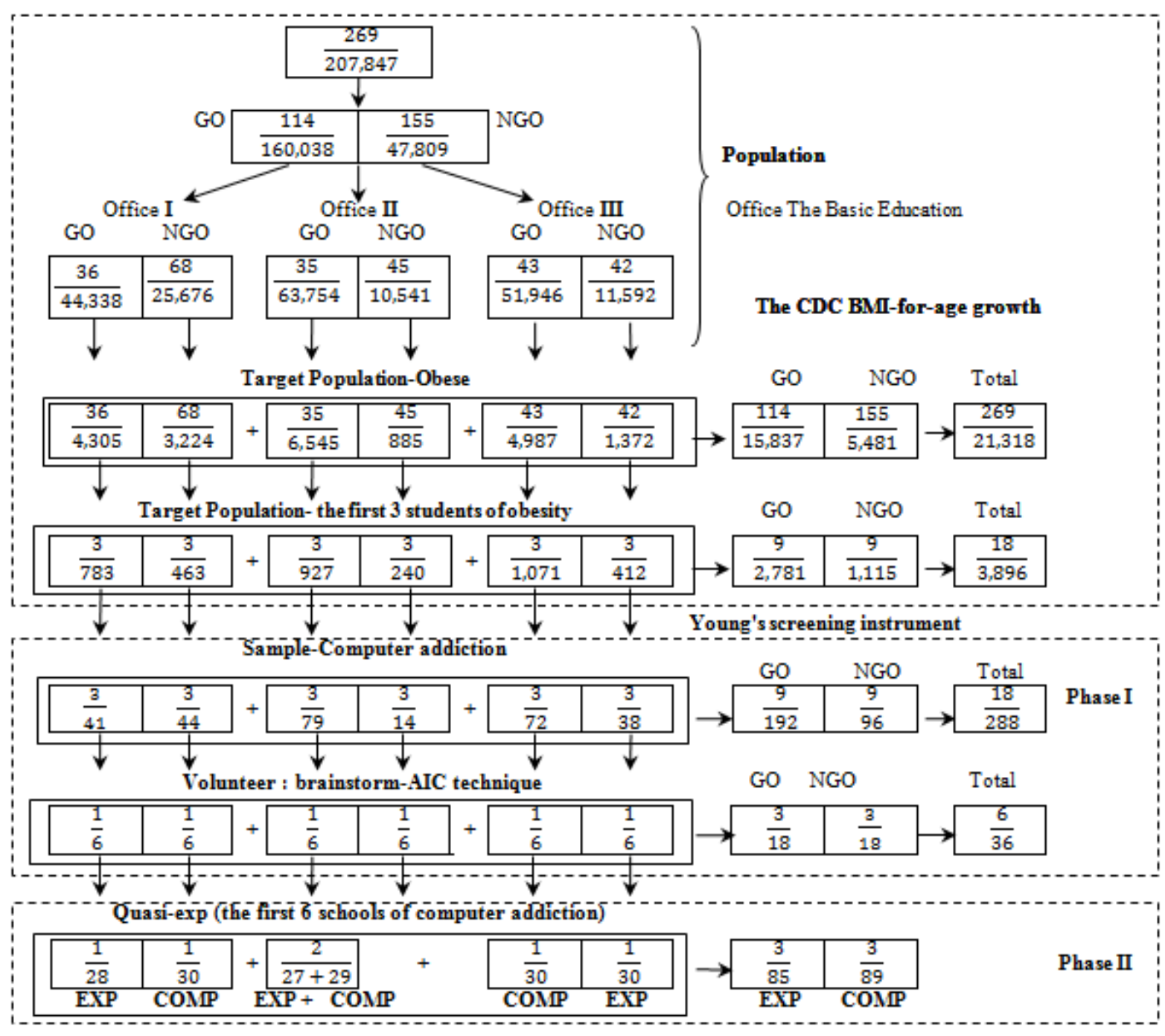

NB $\frac{\mathrm{X}}{\mathrm{y}}$ means $\frac{\text { number of school }}{\text { number of student }}$

EXP means Experimental groups

COMP means Comparison groups

Figure 3. Samples selection 


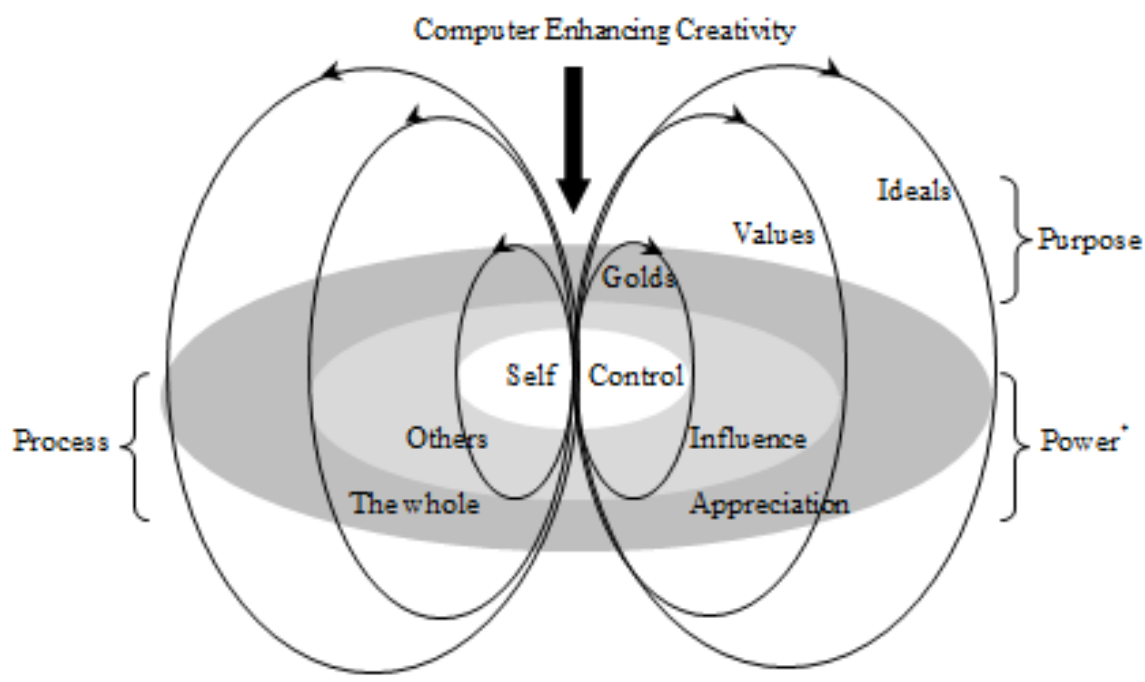

Power*
Appreciation : Causes of computer addiction
Physical \& Social Impact.
Shared recognition \& awareness of computer addiction.
Influence : Utilized computer, enhancing ability to attract attention.
Utilized computer, create portfolio. Advanced computer, create intellectual, Modern child, thought \& use
wisely.
Do the right thing in the right way with the "right" attitude.
Control : Training Computer use \& creativity.

Figure 4. The AIC Model

Exp. groups

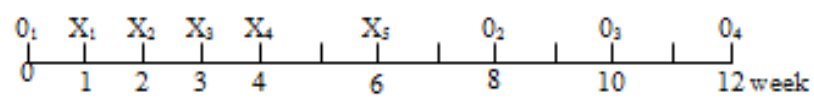

Comp. groups

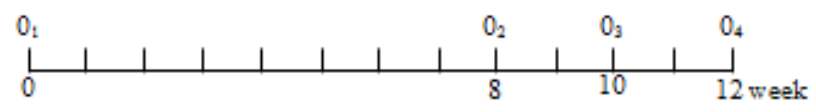

$\mathrm{O}_{1}-\mathrm{O}_{4}$ means measurement in design

$\mathrm{X}_{1}-\mathrm{X}_{5}$ means the training of constructing E-magazines

Figure 5. Quasi-experimental Research planning

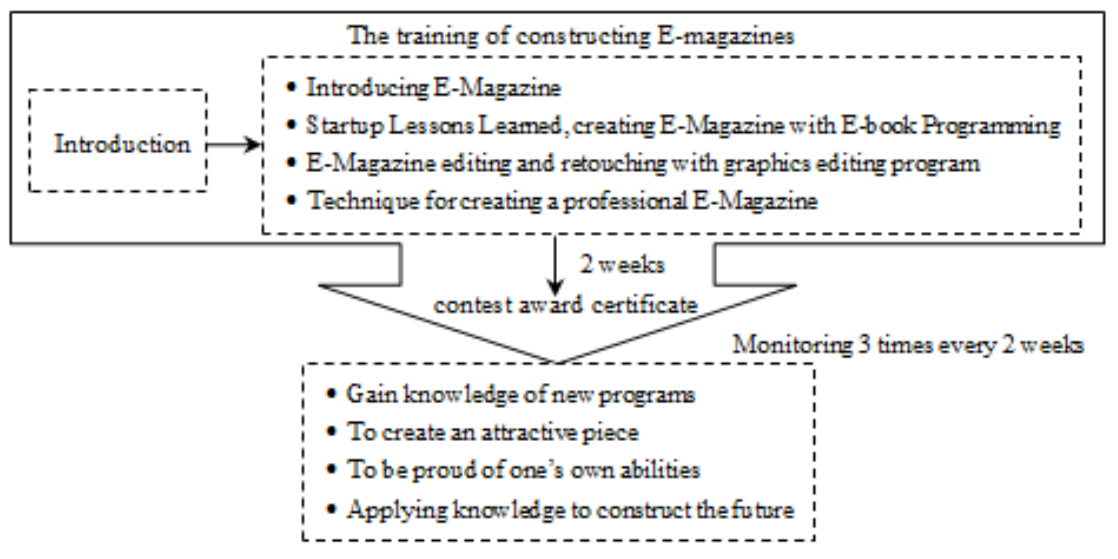

Figure 6. Training: Computer use and creativity 


\section{Apparatus}

The instruments of the study consisted of 4 questionnaires to study the relationship of computer addiction between personal characteristics and cyber behaviors. A Likert scale was used to explore students' perceptions about those items. They have been tried out in two classes of 123 students with the same setting and background; some questions had been deleted to improve the total reliability in each one.

1. A valid and reliable Young's Diagnostic Questionnaire (Young, 2004), to measure the level of internet addiction. This was one of the first psychological tests to assess the problem of pathological use of the internet, consisted of 8 items and was based on the DSM-IVcriteria for pathological gambling. Respondents would be classified as "Internet dependent" if they agreed with five or more of the items.

2. The Maudsley Personality Inventory (Eysenck, 1987), is a self-reported questionnaire designed to assess two major dimensions of personality traits, behavioral and emotional personality. It contained 48 items, 12 for each of the traits, and 12 for the lie scale. Each question has a binary response, 'yes' or 'no'. Each dichotomous item was score 1 or 0 . The Cronbach's Alpha reliability was .69.

3. The health related behaviors' questionnaire was a 20 -item self-report with a 4-point scale. A score of 0 represents no action and a score of 3 represents every day; this reflects typical behaviors of addiction. It consisted of 3 subscales: consumption, exercise and relaxation behavior. The Cronbach's Alpha reliability was .58, .64 and .60, respectively. The severity of addiction was then classified according to the suggested $<0.75,0.75-1.49,1.50-2.24$ and $2.25-3.00$ scores as poor, moderate, fair and normal, respectively.

4. The symptom checklist was a 24-item self-report of clinical and social symptoms, with a 5-point scale(score of 1 represents no problem, score of 5 represents very serious) to describe the extent of the symptoms they had experienced during the previous 2 weeks. The Cronbach's Alpha reliability of those symptoms was .87 and .66 , respectively. The severity of addiction was then classified according to the suggested $<2.00$, 2.00-2.99, 3.00-3.99 and 4.00-5.00 scores as normal, moderate, fair and poor, respectively.

5. A perceived benefits questionnaire included 10 closed-ended questions, with a dichotomous scale. It consisted of 2 subscales: perceived response and perceived computer applications. The Cronbach's alpha reliability was .78 and .69 , respectively. The perceived benefit was then classified according to the suggested $<0.75,0.75-1.49,1.50-2.24$ and $2.25-3.00$ scores as poor, moderate, fair and normal, respectively.

6. The training of constructing E-magazines provided step-by-step ways to stop compulsive computer behaviors and change the perceptions regarding computer use. It includes 1)Introducing E-Magazine 2) Start up lessons learned, creating e-magazine with e-book programming 3) E-Magazine editing and retouching with graphics editing program 4)Technique for creating a professional e-magazine. The model directions are examined and set as a tool, focused on the fact that computer is a means to an end. Plan a workpiece whether to looking for information or entertainment with the end in mind.

The collected data were analyzed, and descriptive statistics were used to demonstrate demographics and properties of psychiatric symptoms based on the data. Independent sample t-test and Pearsons' product-moment correlation were used for hypotheses testing in phase I. Analysis of variance and Post - hoc comparisons using honestly significant difference test (Tukey's HSD.) were used for hypotheses testing in phase II.

\section{Results}

\section{Phase I: The Phase of Survey of Computer Addiction}

To explore computer addiction behavior and related factors, Young's Diagnostic Questionnaire (Young, 2004), a screening instrument for internet dependence based on DSM-IV criteria for pathological gambling was used, which required at least 5 of 8 criteria be met for computer addiction. It indicated that 288 of 3,896 participants were dependent (7.39\%). All of the first five criteria were feeling of self-effacement) $88.54 \%$ (, preoccupation with going online $(86.81 \%)$, increasing amounts of time to achieve satisfaction $(81.25 \%)$, spending more time $(77.08 \%)$ and numerous unsuccessful attempts to cut back (75\%). The 288 participants spent an average of 3 hours 37 minutes online; furthermore, $38.54 \%$ and $4.52 \%$ of the 288 participants claimed that played on the computer over 3 and over 10 hours respectively (Table 1).

Table 1. Screening Instrument for Internet Dependence Used by Young's Diagnostic Questionnaire and Hours Spent on the Computer of 288 Participants

\begin{tabular}{cr}
\hline computer addiction & $\mathrm{n}(\%)$ \\
\hline Internet Dependence used & \\
Escape from problems or relieving moods? & $255(88.54)$ \\
Preoccupation with the internet & $250(86.81)$ \\
Tolerance & $234(81.25)$ \\
Spent time longer than intended & $222(77.08)$ \\
Loss of Control or stop net use & $216(75.00)$ \\
Risked Relationships because of the net? & $188(65.28)$ \\
Withdrawal when attempting to stop net use? & $172(59.72)$ \\
Lying to conceal your involvement with the net? & $150(52.08)$ \\
Hours spent on computer & \\
$\quad \$ 3 h o u r /$ time & $177(61.46)$ \\
$>$ 3hour/time & $111(38.54)$ \\
$\overline{\mathbf{X}}=$ 3hours 37 minutes, $\mathbf{s}=\mathbf{2}$ hours 45 minutes, Range $=1-15$ hours \\
\hline
\end{tabular}


Table 2. Comparison of Computer Addiction Behavior by Socio-demographic Characteristics of the 288 Participants

\begin{tabular}{|c|c|c|c|}
\hline \multicolumn{2}{|c|}{ Socio-demographic characteristics } & \multirow{3}{*}{$\begin{array}{c}\overline{\mathrm{X}} \pm \mathrm{S} \\
2.34 \pm 0.50 \\
2.00 \pm 0.63\end{array}$} & \multirow{3}{*}{$\begin{array}{c}\text { t, F value (p) } \\
\text { t } 3.51^{*}(<.001)\end{array}$} \\
\hline \multirow{2}{*}{ Sex } & Male & & \\
\hline & Female & & \\
\hline \multirow{2}{*}{ Growth Development } & Overweight & $1.96 \pm 0.61$ & \multirow{2}{*}{$\mathrm{t} 1.21(.115)$} \\
\hline & Obese & $2.12 \pm 0.59$ & \\
\hline \multirow{3}{*}{ Education Level } & 1) Secondary education VI & $200 \pm 0.59$ & \multirow{3}{*}{$\begin{array}{l}\text { F } 2719^{*}(.035) \\
\text { paired wise } 1^{*} 3\end{array}$} \\
\hline & 2) Secondary education VII & $2.13 \pm 0.57$ & \\
\hline & 3) Secondary education VIII & $2.31 \pm 0.68$ & \\
\hline \multirow{3}{*}{ Grade Point Average } & 1) $<2.50$ & $2.14 \pm 0.56$ & \multirow{3}{*}{$\begin{array}{l}\text { F } 2.547^{*}(.042) \\
\text { paired wise } 1^{*} 3\end{array}$} \\
\hline & 2). 50-2 99 & $2.03 \pm 0.72$ & \\
\hline & 3) $\geq 3.00$ & $1.80 \pm 0.57$ & \\
\hline \multirow{5}{*}{ Parent's Education Level } & 1) Primary & $222 \pm 0.60$ & \multirow{5}{*}{$\begin{array}{l}\text { F } 3.034^{*}(.010) \\
\text { paired wise } 2^{*} 4\end{array}$} \\
\hline & 2) Secondary & $227 \pm 0.55$ & \\
\hline & 3) Post-Secondary & $2.06 \pm 0.68$ & \\
\hline & 4) Bachelor's Degree & $1.87 \pm 0.63$ & \\
\hline & 5) Post Bachelor's & $1.90 \pm 0.47$ & \\
\hline
\end{tabular}

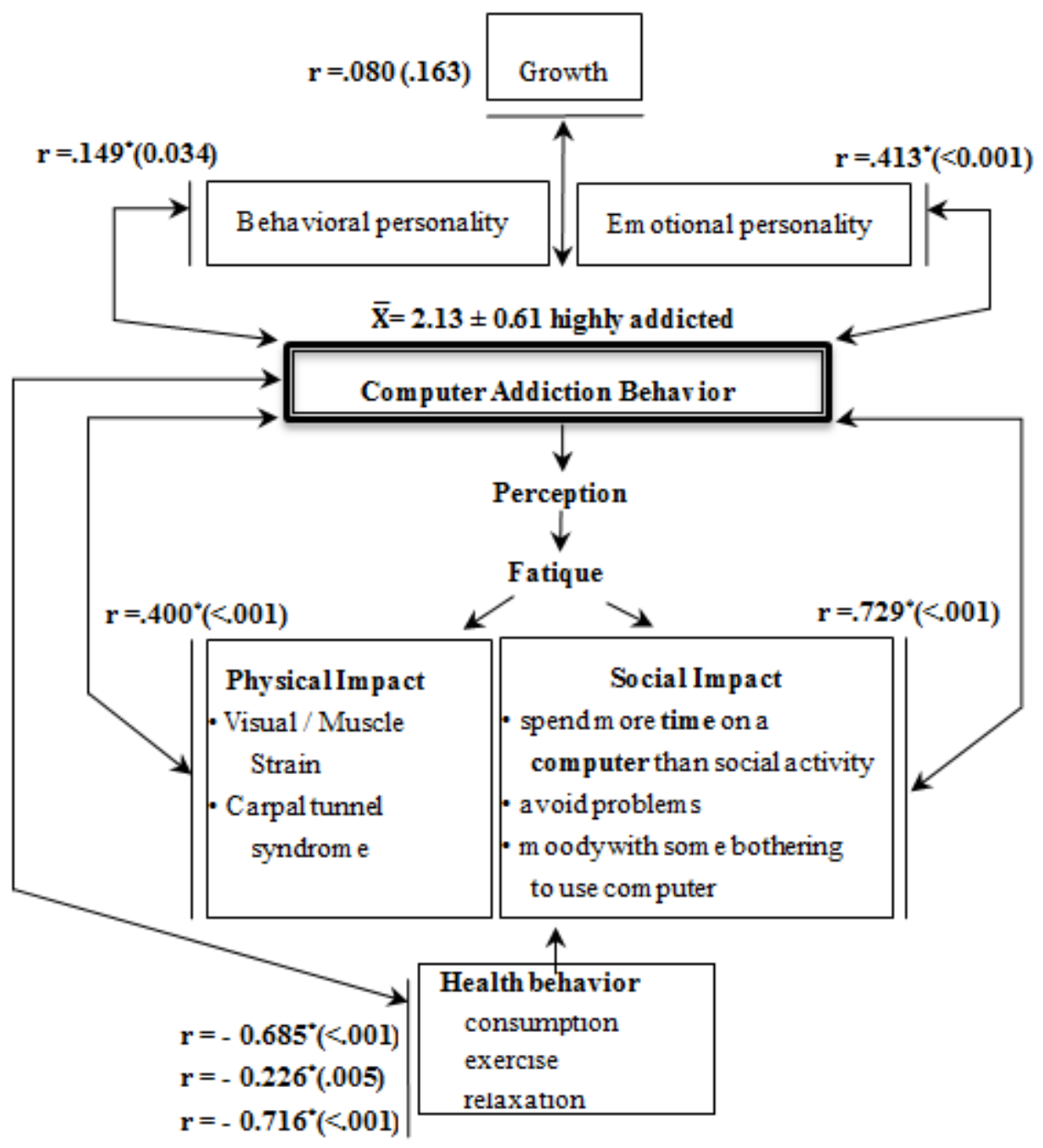

Figure 7. The correlations between heath factors and computer addiction behavior 
Research hypothesis: computer addiction behavior is different in socio-demographic characteristics

The comparison of computer addiction behavior by socio-demographic characteristics of the 288 participants indicated that the ratio of male to female was 2.20:1. A dependent $t$ - test showed the mean computer addiction score of males were statistically higher than females $(\mathrm{t}=3.51$, $\mathrm{p}<.001$ ). Analysis of variance showed a statistically significant difference in computer addiction scores for the education levels $(\mathrm{F}=2.72, \mathrm{p}=.04)$. Post - hoc comparisons indicated that the mean score for education level VIII ( $\overline{\mathrm{X}}=2.31 \pm 0.68)$ was statistically higher than education levelVI( $\bar{X}=2.00 \pm 0.59)$. And it showed a statistically significant difference in computer addiction scores for the Grade Point Averages $(\mathrm{F}=2.55, \mathrm{p}=.04)$. Post - hoc comparisons indicated that the mean score for $\mathrm{GPA}<2.50(\overline{\mathrm{X}}=2.14 \pm 0.56)$ was statistically higher than $\mathrm{GPA} \geq 3.00(\overline{\mathrm{X}}=1.80 \pm 0.57)$. And it showed a statistically significant difference in computer addiction scores for the parent's education levels $(\mathrm{F}=3.03, \mathrm{p}=.01)$. Post - hoc comparisons indicated that the mean score for secondary level $(\overline{\mathrm{X}}=2.27 \pm 0.55)$ was statistically higher than bachelor's degree $(\bar{X}=1.87 \pm 0.63)($ Table2).

Research hypothesis: computer addiction behavior were associated with related factors

The correlation between computer addiction behavior and related factors were listed, the analysis of the data, using the Pearson product - moment correlation coefficient, implied that there were statistically meaningful negative correlation between computer addiction score and consumption behavior( $\mathrm{r}=-.685, \mathrm{p}<.001)$, persistence of relaxation deprivation $(\mathrm{r}=-.716, \mathrm{p}<.001)$ and the lack of exercise $(\mathrm{r}=$ $-.226, \mathrm{p}=.005)$. There were statistically meaningful positive correlation between computer addiction score and the physical health impact $(\mathrm{r}=.400, \quad \mathrm{p}<.001), \quad$ social impact $(\mathrm{r}=.729, \mathrm{p}<.001)$, behavioral personality $(\mathrm{r}=.149$, $\mathrm{p}=.03)$, and emotional personality $(\mathrm{r}=.413, \mathrm{p}<.001)$. There was no statistically significant correlation between computer addiction score and growth development $(\mathrm{r}=.080, \mathrm{p}=.163)$ (Figure 7).

In the second stage (Phase I), 36 recruited volunteers use brainstorming to generate ideas on AIC technique in order to design the guidelines for solving computer addicted students. The result of a brainstorming session was training of constructing E-magazines. In addition, the results in the phase I, found a risk-focus approach should be implemented in introversion-neuroticism personalities by taking pride in solitary activities, and express own interest in participating in the contest.

\section{Phase II: The Phase of Implement Creative Use of Computer}

To enhance the creativity of computer usage, the experimental groups developed their individuality on a workpiece through the computer e.g., travel workpieces $23.54 \%$, game workpieces $21.18 \%$, interesting matter workpieces $17.6 \%$ and miscellaneous workpieces $37.63 \%$.

\section{Comparison of Perceived Benefits of Computer-based Creativity (Table 3)}

Research hypothesis: The training computer use and creativity will more effective in perceived benefits of computer-based creativity.

In a dependent $\mathrm{t}$ - test, the experimental groups showed perceived benefits of the constructing E-magazines (perceived response and perceived computer applications) statistically significant increase in the posttest when compared with the pretest $(\mathrm{t}=10.57, \mathrm{p}<.001)$. And it showed a statistically significant increase in the experimental groups when compared with the comparison groups in the posttest $(\mathrm{t}=25.08, \mathrm{p}<.001)$. However, there were no statistically significant differences in the comparison groups.

Table 3. Comparison of Perceived Benefits of Using Computer Pre-test and Post-test on 12th Week Within and Between Groups

\begin{tabular}{|c|c|c|c|}
\hline $\begin{array}{l}\text { Perceived benefits of } \\
\text { computer-based creativity }\end{array}$ & $\begin{array}{l}\text { Experimental groups } \\
\qquad \overline{\mathrm{X}}_{ \pm \mathrm{s}}\end{array}$ & $\begin{array}{l}\text { Comparison groups } \\
\overline{\mathrm{X}}_{ \pm \mathrm{s}}\end{array}$ & Ind.t(p) \\
\hline \multicolumn{4}{|c|}{ Perceived Response (item 1-5) } \\
\hline \multicolumn{4}{|c|}{ Enjoyment and excitement } \\
\hline Pre-test & $1.19 \pm 0.39$ & $1.08 \pm 0.15$ & $1.7(0.059)$ \\
\hline \multirow[t]{2}{*}{ Post-test } & $1.29 \pm 0.46$ & $1.07 \pm 0.11$ & $5.55^{*}(<.001)$ \\
\hline & Dep.t $2.39^{*}(.010)$ & Dep.t $1.00(.160)$ & \\
\hline \multicolumn{4}{|c|}{ Perceived Computer Applications (item 6-10) } \\
\hline \multicolumn{4}{|c|}{ Gain knowledge in new technologies } \\
\hline Pre-test & $1.41 \pm 0.50$ & $1.40 \pm 0.49$ & $0.1(0.462)$ \\
\hline \multirow[t]{2}{*}{ Post-test } & $2.00 \pm 0$ & $1.38 \pm 0.43$ & $11.93^{*}(<.001)$ \\
\hline & Dep.t $10.95^{*}(<.001)$ & Dep.t $1.42(.079)$ & \\
\hline \multicolumn{4}{|c|}{ Total (item 1-10) } \\
\hline Pre-test & $1.39 \pm 0.16$ & $1.27 \pm 0.18$ & $1.72(0.052)$ \\
\hline \multirow[t]{2}{*}{ Post-test } & $1.82 \pm 0.12$ & $1.24 \pm 0.17$ & $25.08^{*}(<.001)$ \\
\hline & Dep.t $10.57^{*}(<.001)$ & Dep.t $1.50(.410)$ & \\
\hline
\end{tabular}


Table 4. Comparison of Pre/Post Test Frequency and Duration per Week Within and Between Groups

\begin{tabular}{|c|c|c|c|c|c|c|}
\hline \multirow{2}{*}{ computer usage } & \multicolumn{3}{|c|}{ Frequency (day/week) } & \multicolumn{3}{|c|}{ Duration (hour : minute/week) } \\
\hline & Exp.gr & Comp.gr & $\mathrm{t}(\mathrm{p})$ & Exp.gr & Comp.gr & $\mathrm{t}(\mathrm{p})$ \\
\hline \multicolumn{7}{|c|}{ Playing games online } \\
\hline 1. pre-test & $1.35 \pm .89$ & $1.36 \pm .82$ & $1.36(0.952)$ & $3: 37 \pm 2: 54$ & $3: 10 \pm 3: 17$ & $0.97(0.167)$ \\
\hline 2. $8^{\text {th }}$ week & $1.17 \pm .91$ & $1.29 \pm .85$ & $0.89(0.187)$ & $2: 01 \pm 1: 58$ & $2: 58 \pm 3: 24$ & $3.89^{*}(<.001)$ \\
\hline 3. $10^{\text {th }}$ week & $1.04 \pm .84$ & $1.35 \pm .78$ & $2.54^{*}(0.006)$ & $1: 19 \pm 1: 30$ & $3: 52 \pm 3: 11$ & $6.75^{*}(<.001)$ \\
\hline 4. $12^{\text {th }}$ week & $0.98 \pm .77$ & $1.39 \pm .79$ & $3.50^{*}(<.001)$ & $1: 01 \pm 1: 14$ & $3: 54 \pm 3: 11$ & $7.98^{*}(<.001)$ \\
\hline Exp.gr & \multicolumn{3}{|c|}{ F $\left.3.10^{*}\right) .014$ ) paired wise $1^{*} 3,1^{*} 4$} & \multicolumn{3}{|c|}{ F $28.70^{*}(<.001)$ paired wise $1^{*} 2,1^{*} 3,1^{*} 4,2^{*} 3,2^{*} 4$} \\
\hline Comp.gr & \multicolumn{3}{|c|}{ F 0.23 (.439) paired wise NS } & \multicolumn{3}{|c|}{ F $1.02(.383)$ paired wise NS } \\
\hline \multicolumn{7}{|c|}{ Surfing the internet } \\
\hline 1. pre-test & $2.01 \pm 1.22$ & $2.30 \pm 1.29$ & 1.53(.064) & $0: 56 \pm 0: 53$ & $0: 51 \pm 0: 56$ & $0.63(.266)$ \\
\hline 2. $8^{\text {th }}$ week & $2.07 \pm 1.25$ & $2.16 \pm 1.29$ & $0.45(.377)$ & $0: 39 \pm 0: 43$ & $0: 46 \pm 0: 52$ & $0.89(.189)$ \\
\hline 3. $10^{\text {th }}$ week & $2.29 \pm 1.31$ & $2.20 \pm 1.11$ & $0.50(.309)$ & $0: 30 \pm 0: 27$ & $0: 49 \pm 0: 45$ & $3.50 *(<.001)$ \\
\hline 4. $12^{\text {th }}$ week & $2.39 \pm 1.35$ & $2.28 \pm 1.09$ & $0.39(.350)$ & $0: 28 \pm 0: 29$ & $0: 51 \pm 0: 45$ & $3.87 *(<.001)$ \\
\hline Exp.gr & \multicolumn{3}{|c|}{ F 1.14(.234) paired wise NS } & \multicolumn{3}{|c|}{ F 8.94*(<.001) paired wise $1^{*} 2,1^{*} 3,1^{*} 4$} \\
\hline Comp.gr & \multicolumn{3}{|c|}{ F 0.19(.906) paired wise NS } & \multicolumn{3}{|c|}{ F 0.23(.877) paired wise NS } \\
\hline \multicolumn{7}{|c|}{ Online Entertainment } \\
\hline 1. pre-test & $1.92 \pm 1.47$ & $1.89 \pm 1.56$ & $0.13(.448)$ & $0: 30 \pm 0: 3.1$ & $0: 33 \pm 0: 51$ & $0.46(.325)$ \\
\hline 2. $8^{\text {th }}$ week & $2.01 \pm 1.59$ & $1.78 \pm 1.56$ & $1.13(.095)$ & $0: 14 \pm 0: 17$ & $0: 27 \pm 0: 45$ & $2.52^{*}(.007)$ \\
\hline 3. $10^{\text {th }}$ week & $2.12 \pm 1.57$ & $1.83 \pm 1.31$ & $1.25(.100)$ & $0: 10 \pm 0: 11$ & $0: 34 \pm 0: 37$ & $5.82^{*}(<.001)$ \\
\hline 4. $12^{\text {th }}$ week & $2.34 \pm 1.64$ & $2.04 \pm 1.40$ & $1.29(.102)$ & 0:08 $\pm 0: 09$ & $0: 35 \pm 0: 44$ & $5.67^{*}(<.001)$ \\
\hline Exp.gr & \multicolumn{3}{|c|}{ F 1.11(.344) paired wise NS } & \multicolumn{3}{|c|}{ F $25.05^{*}(<.001)$ paired wise $1^{*} 2,1^{*} 3,1^{*} 4,2^{*} 4$} \\
\hline Comp.gr & \multicolumn{3}{|c|}{ F 0.47(.707) paired wise NS } & \multicolumn{3}{|c|}{ F $0.63(.596)$ paired wise NS } \\
\hline
\end{tabular}

\section{Comparison of Frequency and Duration of Computer Use (Table 4)}

Research hypothesis: The training of constructing E-magazines will more effective in decreased frequency and duration of computer use.

1. Playing games online: An analysis of variance in the experimental groups showed a statistically significant difference on the frequency of playing games online by four follow-up studies $(\mathrm{F}=3.10, \mathrm{p}=.01)$. Post - hoc comparisons indicated that the frequency of playing games online in the $10^{\text {th }}$ week $(\overline{\mathrm{X}}=1.04 \pm 0.84)$ and in the $12^{\text {th }}$ week $(\overline{\mathrm{X}}=0.98 \pm 0.77)$ showed statistically significant less frequency than in the $\operatorname{pretest}(\overline{\mathrm{X}}=1.35 \pm 0.89)$. There was showed a statistically significant difference on the duration of playing games online by follow-up studies( $\mathrm{F}=28.70, \mathrm{p}<.001)$. Post - hoc comparisons indicated that the duration of playing games online in the $8^{\text {th }}$ week $(\overline{\mathrm{X}}=2: 01 \pm 1: 58)$, in the $10^{\text {th }}$ week $(\overline{\mathrm{X}}=1: 19 \pm 1: 30)$ and in the $12^{\text {th }}$ week $(\overline{\mathrm{X}}=1: 01 \pm 1: 14)$ were statistically significant shorter duration than in the pretest $(\bar{X}=3: 37 \pm 2: 54)$, and indicated that in the $10^{\text {th }}$ week $(\bar{X}=1: 19 \pm 1: 30)$ and in the $12^{\text {th }}$ week $(\bar{X}=1: 01 \pm 1: 14)$ were statistically significant shorter duration than in the $8^{\text {th }}$ week $(\bar{X}=2: 01 \pm 1: 58)$.

An independent $t$ - test showed a statistically significant less frequency of playing games online in the experimental groups when compared with the comparison groups in the $10^{\text {th }}$ week $(\mathrm{t}=2.54, \mathrm{p}=.006)$, and in the $12^{\text {th }}$ week $(\mathrm{t}=3.50$, $\mathrm{p}<.001)$. It showed a statistically significant shorter duration of playing games online in the experimental groups when compared with the comparison groups in the $8^{\text {th }}$ week $(\mathrm{t}=3.89$, $\mathrm{p}<.001)$, in the $10^{\text {th }}$ week $(\mathrm{t}=6.75, \mathrm{p}<.001)$, and in the $12^{\text {th }}$ week $(\mathrm{t}=7.98, \mathrm{p}<.001)$.

2. Surfing the internet: An analysis of variance in the experimental groups showed a statistically significant difference on the duration of surfing the internet by follow-up studies $(\mathrm{F}=8.94, \mathrm{p}<.001)$.

Post - hoc comparisons indicated that the duration of surfing the internet in the $8^{\text {th }}$ week $(\overline{\mathrm{X}}=0: 39 \pm 0: 43)$, in the $10^{\text {th }}$ week ( $\bar{X}=0: 30 \pm 0: 27)$, and in the $12^{\text {th }}$ week $(\bar{X}=0: 28 \pm 0: 29)$ were statistically significant shorter duration than in the pretest $(\bar{X}=0: 56 \pm 0: 53)$. There was no statistically significant difference at the $\mathrm{p}<.05$ level on the frequency of surfing the internet.

An independent $\mathrm{t}$ - test showed a statistically significant shorter duration of surfing the internet in the experimental groups when compared with the comparison groups in the $10^{\text {th }}$ week $(\mathrm{t}=3.50, \mathrm{p}<.001)$, and in the $12^{\text {th }}$ week $(\mathrm{t}=3.87$, $\mathrm{p}<.001)$. There was no statistically significant difference at the $p<.05$ level on the frequency of surfing the internet. 
3. Online entertainment: An analysis of variance in the experimental groups showed a statistically significant difference on the duration of online entertainment by follow up studies $(\mathrm{F}=25.05, \mathrm{p}<.001)$. Post - hoc comparisons indicated that the duration of online entertainment in the $8^{\text {th }}$ week $(\bar{X}=0: 14 \pm 0: 17)$, in the $10^{\text {th }}$ week $(\bar{X}=0: 10 \pm 0: 11)$, and in the $12^{\text {th }}$ week $(\bar{X}=0: 08 \pm 0: 09)$ were statistically significant shorter duration than in the pretest $(\bar{X}=0: 30 \pm 0: 31)$. There was no statistically significant difference at the $p<.05$ level on the frequency of online entertainment.

An independent $t$ - test showed a statistically significant shorter duration of online entertainment in the experimental groups when compared with the comparison groups in the $8^{\text {th }}$ week $(\mathrm{t}=2.52, \mathrm{p}=.007)$, in the $10^{\text {th }}$ week $(\mathrm{t}=5.82, \mathrm{p}<.001)$, and in the $12^{\text {th }}$ week $(\mathrm{t}=5.67, \mathrm{p}<.001)$. There was no statistically significant difference at the $p<.05$ level on the frequency of online entertainment.

\section{Discussion}

In phase I, the exploration of computer addiction behavior indicated that the participants were computer dependent 288 out of 3,896$) 7.39 \%$ ), male were more likely than female. This is in accordance with Michael D. DiNicola (2004). They stayed online more frequently for long periods of time, and the most popular were games online. Each user uses different connections and spends a lot of time online, interfering with daily life, school, and relationships. Each kept repeating compulsive internet behavior despite the negative consequences in their offline life. The first five criteria were a feeling of self-effacement) $88.54 \%$, which are directly related to daily functioning(Beard and Wolf, 2004); preoccupation with going online $(86.81 \%)$, that is, the different components of dependence common to other addictive behaviors; increasing amounts of time to achieve satisfaction $(81.25 \%)$; spending more time) $77.08 \%$ ( and numerous unsuccessful attempts to cut back $(75 \%)$.These distortions of thought are considered a maladaptive cognitive distortion that exacerbates individual's computer dependence and results in a diminished self-worth and further symptoms of PIU. This is in accordance with the fact that computer usage behavior in the households' daily life, generalized pathological computer use involves a general overuse of the internet, associated with wasting time online, with no specific purpose, including chat rooms online and dependence on checking e-mail.

Computer addiction commonly refers to an individual's inability to control his or her use of the computer, which eventually causes marked distress and functional impairment in daily life. The findings were that excessive computer usage was statistically adversely correlated to one's health behavior, concern the negative consequences of consumption behavior $(\mathrm{r}=-.685, \mathrm{p}<.001)$, persistence of relaxation deprivation $(r=-.716, p<.001)$ and lack of exercise $(\mathrm{r}=-.226, \mathrm{p}=.005)$. Due to maintaining a sitting posture, some may also suffer from physical health impact( $\mathrm{r}=.400$, $\mathrm{p}<.001)$; concerning visual/muscle strain, carpal tunnel syndrome, and social impact $(\mathrm{r}=.729, \mathrm{p}<. \quad 001)$; and concerning family life and academic performance. Family relationships are seriously disrupted by the decrease in time spent with family, reluctance of engaging in household activity, and increase of conflicts with family in the negotiation for time spent on the computer. Academic problems include a significant drop in grades. Furthermore, computer addiction behavior was statistically correlated to behavioral personality $(\mathrm{r}=.149, \mathrm{p}=.034)$ e.g., feeling of loneliness and social isolation; as well as correlated to emotional personality $(\mathrm{r}=.413, \mathrm{p}<.001)$ e.g., depression, anxiety, compulsivity, escape from emotional difficulties, problematic situations, and personal hardships. This is in accordance with previous research that revealed dependents ranked high in terms of self-reliance, emotional sensitivity and reactivity, vigilance, low self-disclosure, and non-conformist characteristics. This preliminary analysis discusses how such traits may act as triggers of addiction in order to fulfill an unmet psychological need through on-line stimulation.(Young and Rodgers, 1998; Petrie and Gunn, 1998).)

In phase II, the training of constructing E-magazines, a powerful pick up skill, is a developed and effective intervention to reinforce the training on one's own. The experimental groups were surfing on the internet to search for the latest information about functioning well on this new balance, which is, constantly evolving into an essential part of daily living, using the internet for an expressed purpose in a reasonable amount of time to create a workpiece on the computer. They developed their individuality on a workpiece through the computer. All uniquely created workpieces reflect the imagination as the basis of independent thought and attention. At the same time, it allows the positive response and computer applications to be explored and appreciated. The experimental groups perceived more benefits of using the computer in the posttest when compared with the pretest, including perceived response and perceived computer applications.

Furthermore, the experimental groups were able to limit use of the computer with positive choices, develop and viewing skills that result in spending less time online. The experimental groups played games online less frequently and also were likely to spend less time gaming, with a statistical significance at the .05 level. At the same time, enhancing knowledge and skill acquisition through e-magazine, the experimental groups spent far less time online searching and information gathering, doing homework online and online entertainment than the comparison groups, with a statistical significance at the .05 level; however, there was no statistically significant difference in the frequency of those. This is in accordance with previous research on 214 participants that revealed controlled use with corrective strategies includes content-control software, is a more practical goal than total abstinence. In conclusion, findings show that in view of the 
possible negative influence of computer addiction on human life, there is a need to have a thorough understanding the experience of the training of constructing E-magazines. It is time to strike a new balance as in e-magazine, a multifaceted approach to understanding and eliminating the harmful effects through the process of training in creative uses of the computer; setting reasonable internet use goals, ensuing positive response to employ the internet as a helpful tool and sticking to them, providing the signs and symptoms of internet addiction and how to balance life online and off.

The concept of internet addiction as a psychiatric disorder is still in its childhood, increasing reliance on the internet as an essential part of their everyday lives, the problems associated with excessive and problematic use of the internet are also set to rise. The phase of the exploration of computer addiction behavior and related factors offer interesting insights into the phase of implementing creative use of computers; e-magazine, the experimental groups can recognize it early and intervene appropriately. Attending e-magazine can help them work through the challenging issues as well. So a guide to computer addiction is as follows.

1. This course, training computer use and creativity, provides meaningful interactive learning, placing advantages and disadvantages, and preparing learners to use computers in developmentally appropriate ways that match the abilities and interests of learners. This equips them with the skills as independent learners to keep up to date with rapidly changing technologies and to keep ahead in information and communication technologies. The experimental groups could separate internet communication from real life communication. They employ the internet as a helpful tool rather than a source of identity, manage the computer use in their own life well and save valuable time. There is no specific time limit, nor is there any behavioral benchmark.

2. Developing quality software, consisting of interactive e-lessons and e-tutoring, provide them challenges, supporting innovation through the learning experience that is helpful in orienting in the right direction, and keeping them engaged in information technology and computer society. Learners self-regulate their internet time, manage the computer use in their own life well and can initiate many of these themselves. That is the way of building skills to cope in daily life without resorting to compulsive Internet use.

\section{Acknowledgments and Legal Responsibility}

This research was made possible through the addicted computer students in schools under the Office of Basic Education Commission, Bangkok, which is funded by the government funds. We would like to recognize the following individuals for the accomplishment.

We are grateful to the teachers for their early and continuous involvement in coordinating and preparing the students. Additionally, we also thank the 36 of recruited volunteers students who participated in the workshop through the AIC process, the participants generously shared their real-life experiences and offered valuable suggestions, computer training courses, for creating relevant, easy-to-understand matters. Finally, this research would not be possible without special recognition is given to the following individuals, 400 students, for their efforts to solve computer addiction through the construct-magazines training.

\section{REFERENCES}

[1] Davis R. A. (2001). A cognitive behavioral model of pathological Internet use. Computer in Human Behavior, 17(2):187-195.

[2] Eysenck, H. J. (1987). Dimensions of Personality. London: Routledge and kengan Paul.

[3] Michael D. DiNicola. (2004). Pathological internet use among college students: the prevalence of pathological internet use and its correlates. (Doctoral dissertation of Philosophy, The Faculty of the college of Education of Ohio University. Retrieved from http://etd.ohiolink.edu

[4] Keith W. Beard and Eve M. Wolf. (2004). Modification in the Proposed Diagnostic Criteria for Internet Addiction. CyberPsychology \& Behavior, 4(3): 377-383.

[5] Petrie, H. and Gunn, D.(1998). Internet Addiction: The Effect of Sex, Age, Depression and Introversion. Retrieved from http://phoenix.herts.ac.uk/ SDRU/Helen/Inter.htm.

[6] Smith, W. E. (2001). Wholeness: The Development of a New Philosophy and Model and Process of Organization. Retrieved from http://odii.com/Library/Theory of AIC.

[7] WHO Expert Consultation. (2004). Appropriate body-mass index for Asian populations and its implications for policy and intervention strategies. Lancet, 363, 157-63.

[8] Young, K. S. (2004). Internet Addiction: The consequences of a new clinical phenomenon. InK. Doyle (Ed.), Psychology and the New Media, 46, 1-14. Thousand Oaks, CA: Corwin

[9] Young, K. S. (2007). Treatment Outcomes with Internet Addicts. CyberPsychology \& Behavior, 10(5): 671-679.

[10] Young, K. S. and Rodgers R. C. (1998). Internet Addiction: Personality Traits Associated with Its Development. Paper presented at the 69th annual meeting of the Eastern Psychological Association. 